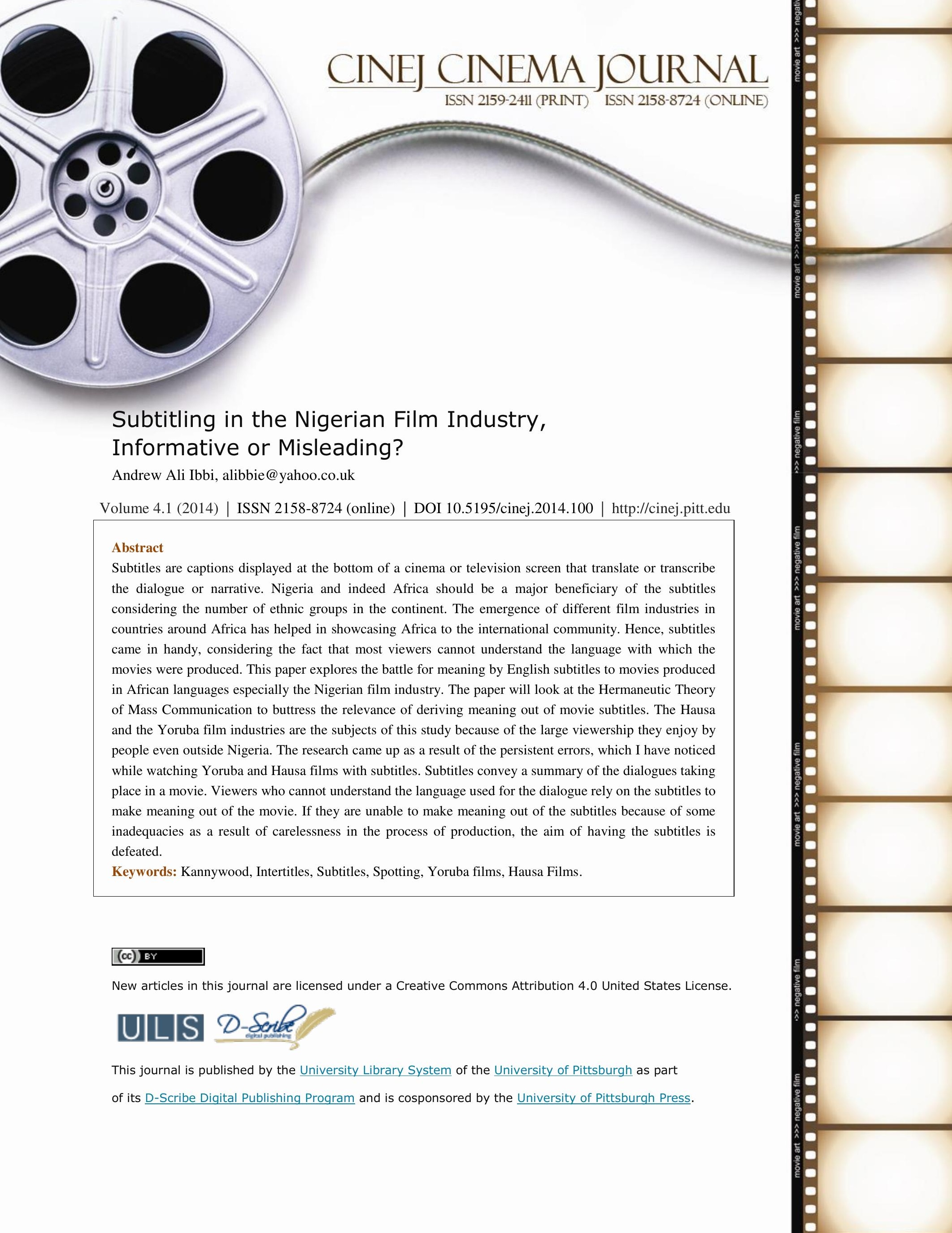




\section{Subtitling in the Nigerian Film Industry, \\ Informative or Misleading?}

\section{Andrew Ali Ibbi}

\section{INTRODUCTION}

Africa is a continent with so many ethnic groups, each with its unique identity. Over the years, the rich cultural heritage of the continent could only be showcased to the world through the screens of Hollywood. However, as technology continues to advance, it is now common knowledge that movies produced from Africa about Africa are on the increase. Many African countries have been shipping their movies abroad. One of such industries that has gained international recognition is the Nigerian film industry, popularly known as Nollywood. The domineering role of the Nigerian film industry cannot be overemphasized. Uchenna (2007) buttressed this point thus: Given the great influence that Nollywood has over African culture, such effect is reinforced by a massive consumption of Nigerian movies by Africans living in Africa and off the shores of Africa. Because of the multilingual nature of Nigeria, it is imperative to bring some form of translations into movies. Subtitling has proved to be the best form of translation a Nigerian movie can give a viewer without disrupting the flow of his/her viewing. This is because voice over which would have been a better choice will not be beneficial to viewers with hearing disabilities. Over the years, technology has helped in shaping subtitles in movies since it came into existence. Georgakopoulou (2006) said since the birth of interlingual subtitling, the way subtitles have been created and presented on screen has gone through many changes, mainly dictated by numerous developments in technology. Though this has brought ease to so many that could not understand the language of dialogue in the movies, it has also become the easy way out for many Africans who find it difficult to catch 
up with the intonation of English language movie stars. A disturbing situation is when subtitles fail to play the roles they are meant for. Since they are like a guide to a person who cannot understand the language of the film, it is expected that they should lead the person instead of misleading him. It becomes discouraging if a viewer cannot understand the sentences in the subtitles. Misspelling can also make understanding difficult especially in cases where the words in question are synonymous to some other words that the viewer has in mind. Subtitling is big business these days, and since the advent of DVDs, the demand for subtitles in many languages has notably increased. This has led to any other person getting involved in the business and since it has become an all comers affairs, there will be no quality control on what is written and hence, there will be all manners of subtitles coming to the audience. Good films like good books should be international. In other words, whatever their language they have a message for the whole world to read. In the case of the latter, it is simple. The book is handed to an expert who translates it. But what of the talking film, which although primarily visual relies on dialogue for its salient points? Wolf (1949).

\section{SUBTITLES DEFINED}

The goal of a subtitle is for it to be "invisible" as text because it is felt to be speech (Thompson 2000). According to Morris (2009), subtitling is many things; not least of which is a way of rendering a foreign language film comprehensible to an audience which does not understand its source language. In a multilingual and multicultural society like Africa, subtitles become very necessary to bridge the gap between a viewer and understanding. Though a movie appeals to the ears and the eyes, the fact that most of the message in embedded in the dialogue calls for the need for the viewers to understand what the dialogue is all about. Subtitles can be 
mono or multilingual in nature. Gambier (2004) in Morris (2009) said "there are also multilingual subtitles which are frequently seen in countries where two or more languages are spoken in the country, for example Belgium or Switzerland." It implies that the interpretation for one language will be displayed above that of the second language if it is a bilingual subtitle.

Since its birth in cinema, subtitles have been used to foster the understanding of viewers that can listen to the voices of the actors and those with hearing disabilities. To this regard, it is obvious that a greater part of the task involved in bridging the gap of understanding between the film and the viewers lies in the people involved in generating the subtitles. Various scholars have found different definitions for subtitles, because of its evolution over time owing to the dynamic nature of technology. Diaz-Cintas (2003) defined subtitles as "displayed written text, which are usually shown at the bottom of the screen, and which give an account of the actors' dialogue and other linguistic information which form part of the visual image (letters, graffiti, and captions) or of the soundtrack (songs)." Bartoll (2004) added this to this definition. "usually, they are presented underneath or at the bottom of the picture, hence their name, and are normally centered." While Morris (2009) pointed out that some can be teletext subtitles which can be added to the picture as the viewer wishes by means of a decoder or character generator in the television set, Ivarsson (2003) added that "alternatively, they can be open subtitles, which are an integral part of the film or programme and cannot be removed according to the wishes of the viewer." What this implies is that in the case of the latter, the viewer does not have control over when the subtitles come up on the screen and his/her only way of calling back the subtitles to move at his speed is either by pausing the movie in order to read through or rewinding over and over again each time the need to call back a particular subtitle arises. In Africa, the open subtitling is what is in use. Whichever way we choose to define subtitles, the 
underlying fact still remains that the subtitle intends to add meaning and understanding of the film in question to the viewers.

\section{A HISTORICAL OVERVIEW OF SUBTITLES}

The advent of sound, however, brought its own problems, as the meanings of the image were complicated with the addition of dialogue and other sound (Pommier 1988) in Morris (2009). This statement tries to bring out how difficult the job of putting together a subtitle can be in today's movie world. This is in contrast to the days of the silent films where the shots are framed to tell the story. Subtitles have evolved over time as technology continues to evolve. Bordwell and Thompson (2008) traced the origin of subtitling thus: "sound filming created a problem for all film producing countries; language barrier threatened to limit export possibilities. Solving this problem of language barrier gave birth to subtitling." Georgakopoulou (2006) explained that in the beginning, subtitles were created by two types of professionals: Technicians in charge of spotting a film, and translators who wrote the subtitles. She explained the process of spotting a film thus: "The spotting of a film was done by defining the in and out times of the subtitles based on the start and finish of actors' utterances or the end of a take. These times were marked on the script and translators were then used to write the subtitles." Ivarsson (2002) pointed out that what we call subtitles today were called intertitles when subtitling started. The name was so because they were titles that appeared in between scenes in the movies. He explained that Norway, Sweden, Hungary, and France quickly took the lead in developing techniques for subtitling films. Gottlieb (2002) in Morris (2009) stated that, 
"the first attested showing of a sound film with subtitles was when The Jazz Singer opened in Paris, on January 26, 1929, with subtitles in French. Later that year, Italy followed suit, and on August 17, 1929, another Al Jolson film, The Singing Fool, opened in Copenhagen, fitted with Danish subtitles."

As the years progressed, technology defined the ease with which subtitling was done. Morris (2009) and Ivarsson (2002) outlined the evolution of the process of subtitling as the optical method, the mechanical and thermal method, the chemical method and finally the laser method. Georgakopoulou (2006) explained that in the mid 1980's, the use of time codes and PCs (Personal Computers) was to revolutionize the process of subtitling and the profession of the subtitler achieved proper status. The computer has made the job of subtitling much easier considering the fact that there are subtitling softwares in computers to assist the subtitler in carrying out his work. "Subtitlers now worked on workstations that comprised a PC with dedicated subtitling software and a video recorder." Georgakopoulou (2006). It is the presence of computers and softwares in subtitling that popularized subtitling in African cinema. Many filmmakers in Nigeria now have access to the subtitling technology, hence the reason for subtitles in most of the movies in the country. Whether these subtitles are fulfilling the primary goal for using them, is something this study has explored.

\section{SUBTITLES AND THEIR RELEVANCE IN FILMS}

Subtitling is one out of the three major audio- visual translation methods, the other two being voiceover and dubbing. The understanding of subtitles requires a number of prerequisite, such as the ability to read and specific competences related to the speed at which subtitles change on the screen. If the pre-requisite is not met, the use of subtitling can be a 
barrier to understanding a film for certain categories of viewers like children, the elderly, immigrants who do not master the language of the host country and hearing impaired persons. The meaning which is the central essence for subtitling must not be distorted so that the intended message is passed across at the end. The moment the meaning in a communication process is misconstrued, the aim of that message is defeated. The French Sociologist, Jacques Derrida while commenting on meaning said "the meaning of a text (anything that contains meaningful signs) depends upon how a particular reader interprets it." Since a word omitted in a sentence or an intended word wrongly spelled could mean a different word, Subtitlers have to be careful with their choice of words and sentence construction. Haralambos and Holborn (2004) said "meaning is always related to the particular context in which it is being discussed, outside that context, the meaning might be quite different. Because subtitles are texts displayed across a screen while action is taking place in a movie, the viewer has to deal with watching the action and reading the text. For this reason, subtitlers have to choose a favourable position to display the text. So that it does not become an obstruction to the flow of the film. Similarly, the choice of the write typefaces and the fonts to use is important, if the subtitles are illegible, the aim of displaying them is defeated. The choice of the colors of the characters generated with respect to the background must also be considered to ensure that the audience gets the message from the film. This clearly shows that subtitling is a business that requires a lot of precision. This leaves the subtitler with a lot of work in his effort to interpret a film in a different language from the language of the film. Morris (2009) explained that subtitling is not the same as translating a written text. Kilbourn (1989) said the subtitler is in a position to be permanently criticized by the audience, and not just by those who understand the source of the language. Though criticisms are bound to come, if the subtitles are done within the rules of the 
game, the message which is the central reason for the subtitle will be passed across. "The information content is determined by the choice and arrangement of words that would best explain and clarify an idea" (Uwuamalam 2002).

\section{SUBTITLES AND THE NIGERIAN FILM INDUSTRY}

The Nigerian film industry, the largest in Africa has gained recognition all over Africa and even in other parts of the world. The attempt by filmmakers in the country to pass a message of cultural heritage to the people has made lots of people to move slightly away from the mainstream English films acted in Nollywood to movies acted in the local languages in the country. The Yoruba movies set the pace for the tribal film industry. Though the English language movies are dominated by a strong Igbo characterization, it is the Hausa and Yoruba film industries that have been churning out movies for the audience. Nigeria, a country located in West Africa prides itself as the most populous black nation in the world. With a population of over 160 million, it has more than 200 ethnic groups. However, three ethnic groups have been identified as the major ethnic groups: Igbo, Hausa and Yoruba (in no order of importance). For internal consumption of movies produced in Nigerian languages, subtitles became a preferred option especially for the literate class. In this case, monolingual subtitling became the best choice and the country's lingua franca, English Language became the language of choice. This choice is is a wise one considering the large number of consumers in other African countries. Sister film industries in the continent have also adopted the monolingual subtitling to reach out to viewers the world over. Especially with respect to movies that have been shot in their indigenous languages. 
Because of the cultural and religious diversity in Nigeria, various ethnic groups have followed the footsteps of the major ethnic groups. Hence we have movies produced in Efik, Igbira, Igede and several other "socalled" minority ethnic groups in the country. While the Yoruba film industry is categorized under Nollywood, the Hausa film industry sees itself as another industry different from Nollywood, it is called Kannywood. Before the advent of subtitles, its products were mostly consumed around the northern part of Nigeria and other Hausa speaking communities around the world.

A common feature between Nollywood and Kannywood apart from being produced in Nigeria is the errors that can easily be noticed in subtitles. Since film editors have the technology for subtitling, most of these filmmakers try to do the job in house so as to save money. This is because most of the films produced in indigenous languages in the country are low budget movies and the executive producers will not want to cough out more money to hire a team of experts to do the subtitling when there are people in house who could do it for a little fee or even gratis. The need for subtitles grew as the movies gained international public viewing owing to the emergence of cable television. DSTV, the cable television network with the widest coverage in Africa has a channel each dedicated to movies produced in Yoruba and Hausa: Africa Magic Yoruba and Africa Magic Hausa. In order to attract more viewership, subtitles have guided those who cannot understand the language to understand the storyline. In most cases, even when the quality of production seems to be filled with technical errors, viewers make do with the storylines. Subtitling in Hausa and Yoruba films are monolingual by nature. Apart from the fact that the viewer has to battle with the issue of moving his eyes from the subtitles to the actions to enjoy the movies, in most of these movies, the viewer has to go through some difficulties trying to decipher what the subtitle is trying to say. Thompson (2000) 
said "the ideal is for a subtitle to appear upon the screen at the exact moment that a person begins to speak, and, conversely, for the subtitle to disappear from the screen at the exact moment when the person ceases to speak." This as the author said is an ideal situation because complications like short statements, gestures, fast speech make it impossible to achieve this even in movies produced with above average budgets. Subtitles associated with the two movie industries have the following errors that I have noticed based on the movies that constitute part of this research.

The color of the characters in the subtitles camouflage with the background of or the clothings worn by the actors. This was a problem noticed with Indian movies watched on Black and White screens in the past. In the days of color television, it makes no sense to use white fonts when the characters are wearing clothes with a shade of white or the background is white. This was noticed in some of the Hausa films.

The subtitles stay longer than necessary, thereby making the viewer to disconnect because there is no connection between the next subtitle on the screen and the action and dialogue in progress. This is common with some of the Hausa and Yoruba films under review.

Some of the subtitles stay too short on the screen, thereby making it impossible for the viewer to read the entire words on display.

Poor sentence construction, thereby leaving the viewer confused over what the subtitler is trying to communicate. Sometimes, it is the omission of an important word that would have served as a connector. In other times, it is the combination of present and past tenses in the same sentence. Sometimes, the subtitler translates directly from his/her mother tongue to English. This is common with the two industries. 
Misspelling of words, which could either render a word meaningless or give it another meaning. Sometimes, it becomes so obvious that the subtitles were not previewed for proper editing before taking the products to the market. It is common with the two industries.

Overcrowding of the bottom of the screen with too many words at a time. This is obviously done because the subtitler feels he is translating the dialogue of the actors.

Some of the words are out of context with what the actors are saying. The actors will be saying something and the subtitles being displayed will be saying the contrary. This becomes difficult to understand the motive of the subtitler. The only reason that comes to mind is that the subtitler is capitalizing on the fact that those reading the subtitles do not understand the language and will believe whatever comes on the screen.

Some of the subtitles do not consider the aspect ratio of the screens as such, some of the texts are lost in the body of the television set. This is more common with some of the Hausa films in the study.

\section{THEORITICAL FRAMEWORK}

Hermeneutic Theory involves the study of understanding, especially by interpreting action and text. According to Baran and Davis (2009), hermeneutics originated when the need for interpreting and understanding the content of the Bible and other sacred books became paramount. The theory sees text as any product of social interaction that serves as a source of understanding. Burrell and Morgan (1979) said hermeneutics is all about the examination of the objectification of the mind. So just like the Holy Bible was the objectification of the early Christians, those that seek to understand it will have to study the text. In the same vein, as the subtitles are the objectification of viewers watching movies in foreign languages, they will 
have to study the text in order to get the meaning of the message. Baran and Davis (2009) agreed to this by saying "another branch of hermeneutics looks for hidden or deep meaning in people's interpretation of different symbol systems, like in media texts." The authors went further to say that this theory is sometimes referred to as the Interpretative Theory.

\section{RECOMMENDATIONS}

Because of the relevance of subtitles to movies produced not only in Nigeria but Africa in general, it has become necessary that proper attention should be given to this process. Having observed the way movies are subtitled in Nigeria, and considering the fact that the economic situation in the country and the issue of piracy is not helping matters, production of Hausa and Yoruba films is higher than their English language films produced in the country. The following are some recommendations that will improve the quality of subtitles of movies produced in indigenous languages so that the aim of the process will not be ridiculed

Subtitling should not be left in the hands of those who do not have a mastery of the English language. There should be a guild for movie subtlers and membership should be restricted to those who have studied English Language at advanced level, preferably at degree level.

Each movie to be subtitled must pass through a competent editor before the subtitled movie is approved.

All subtitled movies must be previewed and errors corrected before final production of the movies.

Movies to be given for international viewership must be ones that will not disgrace the country through subtitles or storyline. 
There should be a synergy between movie producers in the country so that the challenges of the industry will be discussed at some forums organized by members, so that solutions will be proffered immediately. This will help in improving the quality of movies in the country whether produced in English language or in any of the numerous indigenous languages in the country.

All movies produced in the country should be under Nollywood instead of having appendages like Kannywood and others.

\section{CONCLUSION}

Cramer (2009) wrote that the emerging perspective among media scholars is that media audiences are engaged viewers. What this means is that media consumers are not just passive blobs, receiving whatever messages producers create for them. Rather, media consumers are seen as active, as interpreting messages critically, and as resisting messages.

Subtitles are meant to create a message to the viewers and the more the viewers get what they see as misinformation, the more they get discouraged at watching some of the movies produced in local languages in the country. From the study conducted, it is obvious that because of the volume of productions in the two languages under study, subtitles are not well edited before sending movies to the screens of viewers. The major problem in this regard is that movie producers in the country are on a daily increase, irrespective of the quality of the production. Majority of these movies are low budget movies even by Nigerian standards. If films produced in indigenous languages across Nigeria are expected to pass the desired messages they are packaged for, subtitling must be taken as a serious business since majority of the viewers are people who do not understand the language but who are interested in knowing 
about the culture of the people whose language has been used in the country. Subtitles

produced with lots of grammatical errors do not only show the lack of seriousness of the producers but it goes to rub off negatively on the level of education in the country where it is produced. With lots of English language graduates roaming the streets waiting to be hired for this job, there is no excuse for producing error filled subtitles. Especially if the country intends to build on the name it has acquired over time as the largest film industry in Africa.

\section{BIBLIOGRAPHY}

Anderman, G. M. (2003) ed. Translation Today: Trends and perspectives. Clevelon; Multilingual Matters Limited.

Baran, S. J. and Davis, D. K. (2009) Mass Communication Theory: Ferment and Future. Boston: Wardswoth Cengage Learning

Bartoll, E. (2004) "Parameters for the classification of Subtitles." In: Ordrero, P(2004) ed. Topics in Audiovisual Translations. Philadelphia: John Benjamins Publishing Company

Bordwell, D. and Thompson, K. (2008) Film Art: An Introduction. New York: McGraw-Hill

Burrell, G. and Morgan, G. (1979) Sociological Paradigms and Organisation Analysis. London: Heinemann

Cramer, J. M. (2009) Media/History/Society: A Cultural History of U.S. Media. Chichester: Wiley-Blackwell

Diaz-Cintas, J. (2003) “Audiovisual Translation in the Third Millenium.” In: Anderman, G. M (2003) ed. Translation Today: Trends and Perspectives. Clevelon; Multilingual Matters Limited.

Georgakopoulou, P. (2006) Subtitling and Globalisation. Journal of Specialised Translation, Issue 6. London: European Captioning Institute

Haralambos, M. et al (2004) Sociology: Themes and Perspectives. London: Harper Collins

Ivarsson, J. (2002) A Short Technical History of Subtitles in Europe: www.transedit.st/history

Kilbourn, R. (1989) 'They Don't Speak Proper English': A New Look at the Dubbing and Subtitling Debate. The Mordern Language Journal.

Morris, J. (2009) An investigation into the subtitling in French and Spanish Heritage Cinema. London: University of Birmingham 
Ordrero, P. (2004) ed. Topics in Audiovisual Translations. Philadelphia: John Benjamins Publishing Company

Owuamalam, E. (2002) Audio-Visual Medium: Radio, TV, Film and Theatre. Owerri: Top Class Publishers

Thompson, P. (2000) Getting Beyond "Read 'em, Quick!" Some practical, Slow Noteson Subtitles and Superimpositions. www.chicagomediaworks.com

Uchenna, O. (2009) Nollywood: The Influence of the Nigerian Movie Industry on African Culture. www.authorsden.com 